\title{
Reação de seleções do limão Cravo à infecção no tronco por Phytophthora nicotianae e à estirpe protetiva PIAC do vírus da tristeza dos citros
}

\author{
Silvia Blumer ${ }^{1} \&$ Jorgino Pompeu Junior ${ }^{2}$
}

\section{RESUMO}

O limão Cravo (Citrus limonia), principal porta enxerto da citricultura brasileira, apresenta média resistência à gomose de Phytophthora. Este estudo avaliou a resistência à infecção no tronco por Phytophthora nicotianae e a suscetibilidade a estirpe protetiva PIAC do vírus da tristeza dos citros de seleções de limão Cravo enxertadas com um clone nucelar de laranja Valencia (C. sinensis) premunizado com a estirpe PIAC do vírus da tristeza dos citros. O delineamento experimental foi o inteiramente casualizado com seis porta-enxertos, sendo cinco plantas inoculadas e cinco não inoculadas, totalizando 60 plantas. Na véspera da inoculação do patógeno, foram medidos o diâmetro do porta-enxerto e o índice SPAD e 61 dias após, o diâmetro do porta-enxerto, o comprimento e altura das lesões e o índice SPAD. A suscetibilidade à tristeza foi avaliada pela observação de sintomas de deficiências nutricionais nas plantas e de caneluras no tronco das seleções. As seleções de limão Cravo não diferiram entre si quanto ao diâmetro e altura da lesão porem diferiram quanto à área da lesão. Os limões Cravos Hangleson, Kirumakki, Poona e Tuningmeng apresentaram as menores áreas lesionadas sendo considerados os mais resistentes a gomose de tronco causada por P. nicotianae. Nenhuma das combinações mostrou sintomas de suscetibilidade à estirpe PIAC do vírus da tristeza dos citros presente na copa da laranjeira Valência.

Termos de indexação: Citrus limonia, porta-enxerto, doença, gomose.

\section{Reaction of Rangpur lime selections to trunk infection by Phytophthora nicotianae and protective PIAC strain of citrus tristeza virus}

\section{SUMMARY}

Rangpur lime (Citrus limonia), the most important rootstock in the Brazilian citriculture, shows medium resistance to Phytophthora gummosis. This study evaluated the resistance to trunk infection by Phytophthora nicotianae and the susceptibility to the strain PIAC of the citrus tristeza virus of six selections of this rootstock budded with a Valencia nucellar orange clone (C. sinensis) carrying the strain PIAC-CTV. The experimental design was a completely randomized drawing with six rootstocks, with five plants inoculated and five non-inoculated, totaling 60 plants. Evaluations performed one day before and 61 days after pathogen inoculation included the diameter of the

\footnotetext{
${ }^{1}$ Centro Universitário Fundação de Ensino Octavio Bastos, São João da Boa Vista, SP, Brasil

${ }^{2}$ Centro APTA Citros Sylvio Moreira, Instituto Agronômico, Cordeirópolis, SP, Brasil

Autor correspondente: Silvia Blumer, Centro Universitário Fundação de Ensino Octavio Bastos, Av. Dr. Octávio Bastos, 2.439, São João da Boa Vista, SP, Brasil. E-mail: silvia.blumer@unifeob.pro.br
} 
rootstock trunk and SPAD value and length and diameter of trunk lesions. The susceptibility PIAC-CTV was evaluated by the observation of symptoms of nutritional deficiencies in the plants and the occurrence of stem-pitting in the trunk of the selections. The selections of Rangpur lime did not differ in relation to the diameter and height of the lesion but differed in relation to the area of the lesion. Hangleson, Kirumakki, Poona and Tuningmeng presented the smallest lesion areas and were considered the most resistant to P. nicotianae trunk gummosis. None of the combinations showed symptoms of susceptibility to the PIAC strain of citrus tristeza virus present in the canopy of Valencia sweet orange.

Index terms: Citrus limonia, rootstock, disease, gummosis.

\section{INTRODUÇÃO}

Desde a década de 1960 o limão Cravo (Citrus limonia L. Osbeck) tem sido o principal porta-enxerto da citricultura brasileira por facilidade de formação das mudas, compatibilidade com todas as copas, início de produção precoce, altas produções de frutos de boa qualidade, grande resistência à seca, além da tolerância à tristeza. Essas características mantêm-no preferido pelos viveiristas e citricultores apesar de sua suscetibilidade ao declínio dos citros (Beretta et al., 1994), a morte súbita dos citros (Pompeu Junior \& Blumer, 2008) e media resistência à gomose de Phytophthora (Feichtenberger et al., 2005).

O Centro de Citricultura Sylvio Moreira do Instituto Agronômico do Estado de São Paulo (CCSM) possui quase uma centena de seleções e híbridos do limão Cravo, introduzidas do Brasil e do exterior, que vêm sendo avaliadas quanto às características exigidas dos potenciais porta-enxertos utilizáveis na citricultura paulista, entre as quais a resistência à infecção de tronco e das raízes pelo oomiceto Phytophthora nicotianae Breda de Haan a espécie predominante no estado de São Paulo (Feichtenberger et al., 2005).

A prevenção requer a utilização de porta-enxertos resistentes, razão pela qual o conhecimento do grau de resistência de potenciais porta-enxertos constitui um dos critérios de seleção dos programas de melhoramento.

Os primeiros testes de resistência em citros à Phytophthora spp. foram realizados por Fawcett (1923), que estabeleceu a natureza parasítica do patógeno e por Klotz \& Fawcett (1930), que desenvolveram o método de inoculação artificial do patógeno no tronco e, pela avaliação da área da lesão resultante, verificaram a resistência de espécies e variedades de Citrus spp. e gêneros relacionados.

Em São Paulo, estudos mostraram que os porta-enxertos diferem na suscetibilidade às infecções de tronco por $P$. nicotianae e $P$. citrophthora sendo mais suscetíveis as laranjas doces e menos suscetíveis os trifoliatas (Poncirus trifoliata Rafinesque) e o citrumelo Swingle (C. paradisi Macfaden x P. trifoliata) (Rossetti, 1947). De modo geral, o limão Cravo apresenta média resistência às infecções de tronco causadas por estes patógenos, existindo variantes entre as seleções, sendo mais resistentes Santa Bárbara e EEL e mais suscetíveis Japanshe citroen, limão Cravo Periforme e Borneo red lime (Muntaner et al., 1976).

Este trabalho avaliou a resistência de seleções do limão Cravo à inoculação no tronco de $P$. nicotianae $\mathrm{e}$ a suscetibilidade à estirpe protetiva PIAC do vírus da tristeza dos citros.

\section{MATERIAL E MÉTODO}

Foram estudadas seis seleções de limão Cravo introduzidas por sementes em março de 2010 da Universidade da Califórnia a seguir relacionadas: Hangleson Red Lime, Kirumakki Rangpur Lime, Knorr Rangpur Lime, Poona Rangpur Lime, Srirampur Rangpur Lime e Tuningmeng Rangpur Lime.

Ainda em março procedeu-se a semeadura em tubetes e 78 dias após, as plântulas foram selecionadas visando à exclusão dos híbridos e uniformidade dos seedlings e transplantadas para sacos plásticos de cinco litros, contendo substrato Rendimax ${ }^{\circledR}$ mais Osmocote ${ }^{\circledR}$ 18-5-9 tendo recebido os tratos culturais adequados à formação de mudas cítricas de boa qualidade. Em outubro de 2010, as plantas foram enxertadas com borbulhas retiradas de laranjeira Valência (C. sinensis L. Osbeck) clone nucelar, premunizado com estirpe fraca protetiva (PIAC) do vírus da tristeza dos citros (Müller et al., 1999) pertencente ao Banco de Matrizes Premunizadas do CCSM. A formação das mudas foi toda desenvolvida em casa de vegetação revestida por telado antiafídeo. 
Para avaliar a resistência dos porta-enxertos à $P$. nicotianae, dez mudas uniformes de laranjeiras Valencia enxertadas em cada seleção de limão Cravo, foram transferidas em março de 2012 para sala com ambiente climatizado, com temperatura média de $26,3^{\circ} \mathrm{C}$ e umidade relativa do ar de $82 \%$ e iluminação artificial constante. Após duas semanas de adaptação as plantas foram inoculadas com o isolado LRS 95/03 selecionado pela maior agressividade dentre dez isolados provenientes da Unidade de Pesquisa e Desenvolvimento de Sorocaba da APTA/SAA (Pio, 2005). O isolado cresceu em meio BDA armazenado a $25^{\circ} \mathrm{C} \pm 2 \mathrm{com}$ fotoperíodo de $12 \mathrm{~h}$ por sete dias até o momento da inoculação.

Precedendo a inoculação, as folhas foram removidas até a altura de $15 \mathrm{~cm}$ do colo das plantas e a superfície do caule desinfetada com álcool $70 \%$. Para a coleta do inóculo, foi utilizado furador com $0,5 \mathrm{~cm}$ de diâmetro previamente imergido em álcool $96^{\circ} \mathrm{GL}$ e flambado, e a seguir, realizada a aquisição dos discos de micélio do patógeno perfurando-se a colônia fúngica na placa de Petri. A inoculação consistiu na perfuração da haste do porta-enxerto a $10 \mathrm{~cm}$ de altura do colo com o mesmo furador utilizado na coleta do inóculo e a colocação do micélio com ajuda de agulha histológica. A região da inoculação foi protegida com algodão envolvido por esparadrapo cirúrgico, livre de zinco, e umedecida diariamente com água destilada.

O delineamento experimental foi o inteiramente casualizado com seis porta-enxertos, cada um dos quais teve cinco plantas inoculadas e cinco não inoculadas, totalizando 60 plantas.

Decorridos 61 dias da inoculação, utilizando paquímetro digital, foram mensurados o comprimento e a largura da lesão sob a casca e calculada a área (A) da lesão utilizando a fórmula da área da elipse $(\mathrm{A}=0,785 \mathrm{x}$ comprimento $\mathrm{x}$ largura) por representar melhor a forma da lesão.

Os danos causados as mudas pela presença da P. nicotianae foram avaliados pela comparação dos diâmetros dos troncos dos porta-enxertos e pelo Índice SPAD (teor relativo de clorofila na folha) medidos antes e após a inoculação do patógeno.

Para tanto, na véspera das inoculações e no dia da mensuração das lesões foram medidos os diâmetros dos porta-enxertos pouco acima da região da inoculação e o Índice SPAD. Este índice foi obtido utilizando o clorofilômetro Soil Plant Analysis Development (SPAD - 502) e representa valores proporcionais aos do teor de clorofila presente na folha sendo utilizado na avaliação de estresses abióticos e bióticos em diversas culturas (Minolta, 1989). Este índice foi medido em cada planta em duas folhas da laranjeira Valência próximas da região de enxertia e em duas folhas próximas ao ápice das plantas. A média aritmética dessas quatro medições foi utilizada nas análises estatísticas.

Os dados obtidos foram analisados utilizando o aplicativo SASM-Agri (Canteri et al., 2001) sendo submetidos à análise de variância e as medias comparadas pelo teste de Scott-Knott a 5\% de probabilidade (Scott \& Knott, 1974).

\section{RESULTADOS E DISCUSSÃO}

A reação das seleções de limão Cravo a inoculação de P. nicotianae é apresentada na Tabela 1. Não foram constatadas diferenças significativas entre os diâmetros e as alturas das lesões entre as seleções de limão Cravo.

Porém, os limões Cravo diferiram quanto à área lesionada pela $P$. nicotianae. As seleções Srirampur $\left(101,8 \mathrm{~mm}^{2}\right)$ e $\operatorname{Knorr}\left(100,2 \mathrm{~mm}^{2}\right)$ apresentaram as maiores lesões enquanto que as seleções: Hangleson $\left(77,1 \mathrm{~mm}^{2}\right)$, Kirumakki $\left(77,1 \mathrm{~mm}^{2}\right)$, Poona $\left(81,1 \mathrm{~mm}^{2}\right)$ e Tuningmeng $\left(85,5 \mathrm{~mm}^{2}\right)$ exibiram as menores áreas lesionadas.

Decorridos 61 dias da inoculação do patógeno, a presença da P. nicotianae não induziu diferenças significativas entre os tratamentos controles e inoculados quer no diâmetro dos porta-enxertos quer nos valores do Índice SPAD. Fez exceção a seleção Srirampur que apresentou maior teor médio de clorofila nas plantas inoculadas que nas plantas sadias.

Entre as seleções não inoculadas não foram constatadas diferenças significativas no diâmetro dos porta-enxertos e nos Índices SPAD, quer no início quer no final do experimento,

O vigor das seleções de limão Cravo estimado pela comparação dos diâmetros médios dos tratamentos não inoculados foi semelhante para todas as seleções. O maior diâmetro foi exibido pelo limão Cravo Srirampur (19,5 mm) e o menor, (16,9 mm), pelo limão Cravo Kirumakki.

Decorridos 20 meses da enxertia, nenhuma das plantas mostrou deficiências nutricionais e caneluras no tronco das seleções que indicassem suscetibilidade à estirpe PIAC do vírus da tristeza dos citros presente nas borbulhas da laranjeira Valência utilizada como copa. 
Tabela 1. Dimensões médias da lesão, diâmetros médios dos porta-enxertos e índice SPAD de mudas de laranjeiras Valencia enxertadas em seleções de limão Cravo inoculadas ou não com Phytophthora nicotianae, ao final de 61 dias

\begin{tabular}{|c|c|c|c|c|c|c|c|c|c|}
\hline \multirow{3}{*}{ Limão Cravo } & \multicolumn{3}{|c|}{ Dimensões médias da lesão } & \multicolumn{3}{|c|}{$\begin{array}{l}\text { Diâmetro médio } \\
\text { do porta-enxerto }\end{array}$} & \multicolumn{3}{|c|}{ Índice SPAD } \\
\hline & Diâmetro & Altura & Área & Controle & Inoculado & C.V. & \multirow{2}{*}{ Controle } & \multirow{2}{*}{ Inoculado } & \multirow{2}{*}{$\frac{\text { C.V. }}{\%}$} \\
\hline & \multicolumn{2}{|c|}{------- mm ------- } & $\mathrm{mm}^{2}$ & \multicolumn{2}{|c|}{-------- mm ------- } & $\%$ & & & \\
\hline Hangleson & $8,1 \mathrm{~A}^{*}$ & $12,3 \mathrm{~A}$ & $77,1 \mathrm{~B}$ & $17,3 \mathrm{Aa}$ & $19,1 \mathrm{Aa}$ & 10,9 & $68,0 \mathrm{Aa}$ & $64,4 \mathrm{Aa}$ & 4,9 \\
\hline Knorr & $8,8 \mathrm{~A}$ & $14,5 \mathrm{~A}$ & $100,2 \mathrm{~A}$ & $17,8 \mathrm{Aa}$ & $17,7 \mathrm{Aa}$ & 10,6 & $67,8 \mathrm{Aa}$ & $69,8 \mathrm{Aa}$ & 7,4 \\
\hline Kirumakki & $7,7 \mathrm{~A}$ & $12,6 \mathrm{~A}$ & $77,1 \mathrm{~B}$ & $16,9 \mathrm{Aa}$ & $16,9 \mathrm{Aa}$ & 12,2 & $69,2 \mathrm{Aa}$ & $70,4 \mathrm{Aa}$ & 8,6 \\
\hline Poona & $8,2 \mathrm{~A}$ & $12,5 \mathrm{~A}$ & $81,1 \mathrm{~B}$ & $17,8 \mathrm{Aa}$ & $17,3 \mathrm{Aa}$ & 7,5 & $70,3 \mathrm{Aa}$ & $69,1 \mathrm{Aa}$ & 5,9 \\
\hline Srirampur & $9,9 \mathrm{~A}$ & $13,2 \mathrm{~A}$ & $101,8 \mathrm{~A}$ & $19,5 \mathrm{Aa}$ & $18,3 \mathrm{Aa}$ & 7,1 & $66,5 \mathrm{Ab}$ & $71,0 \mathrm{Aa}$ & 3,1 \\
\hline Tuningmeng & $8,4 \mathrm{~A}$ & $12,8 \mathrm{~A}$ & $85,5 \mathrm{~B}$ & 17,1 Aa & $18,4 \mathrm{Aa}$ & 8,9 & $72,0 \mathrm{Aa}$ & $68,3 \mathrm{Aa}$ & 8,1 \\
\hline C.V. \% & 14,69 & 14,80 & 19,50 & 9,07 & 10,07 & & 5,25 & 8,12 & \\
\hline
\end{tabular}

*Valores seguidos de mesma letra maiúscula na coluna e minúscula na linha não diferem entre si pelo teste de Scott-Knott ao nível de $5 \%$ de probabilidade.

\section{CONCLUSÕES}

As seleções de limão Cravo não diferiram entre si quanto ao diâmetro e altura da lesão causada pela inoculação no tronco de $P$. nicotianae porem diferiram quanto à área da lesão.

Os limões Cravos Hangleson, Kirumakki, Poona e Tuningmeng apresentaram as menores áreas lesionadas sendo considerados os mais resistentes a gomose de tronco causada por P. nicotianae.

Nenhuma das combinações mostrou sintomas de suscetibilidade à estirpe protetiva PIAC do vírus da tristeza dos citros presente na copa da laranjeira Valência.

\section{AGRADECIMENTOS}

Os autores agradecem ao CNPq pela concessão dos recursos necessários a introdução do germoplasma e a realização do presente estudo (Processo $\mathrm{MCT} / \mathrm{CNPq}$ Universal 475553/2010-1), ao Fundo de Defesa da Citricultura (Fundecitrus) pelo empréstimo de veículo e aos pesquisadores Eduardo Feichtenberger e Rafael Pio, pela cessão e seleção do isolado LRS 95/03 de Phytophthora nicotianae utilizado neste trabalho.

\section{REFERÊNCIAS}

Beretta, M. J. A. G., Pompeu Junior, J., Derrick, K. S., Lee, R. F., Barthe, G. A., \& Hewitt, B. G. (1994) Evaluation of rootstocks in Brazil for field resistance to declinio. In Proceedings 7th International Citrus Congress (p. 841-843). Catania: International Society of Citriculture.

Canteri, M. G., Althaus, R. A., Virgens Filho, J. S., Giglioti, E. A., \& Godoy, C. V. (2001). Sasm - Agri: Sistema para análise e separação de médias em experimentos agrícolas pelos métodos Scott - Knott, Tukey e Duncan. Revista Brasileira de Agrocomputação, 1, 18-24.

Fawcett, S. (1923). Gummosis of citrus. Journal of Agricultural Research, 24, 191-236.

Feichtenberger, E., Bassanezi, R. B., Spósito, M. B., \& Belasque Junior, J. (2005) Doenças dos citros. In H. Kimati, L. Amorim, A. Bergamin Filho, L. E. A. Camargo \& J. A. M. Rezende (Eds.), Manual de Fitopatologia: Doenças das plantas cultivadas (4. ed., p. 239). São Paulo: Editora Agronômica Ceres.

Klotz, L. J., \& Fawcett, H. T. S. (1930). The relative resistance of varieties and species of citrus to Phythiacystis gummosis and other bark diseases. Journal of Agricultural Research, 41, 415-425.

Minolta. (1989). Chlorophyll meter SPAD-502. Instruction manual (22 pp.). Osaka, Japan: Minolta Co.

Müller, G. W., Targon, M. L. N., \& Machado, M. A. (1999). Trinta anos de uso do clone pré-imunizado 'Pêra IAC' na citricultura paulista. Laranja, 20, 399-408.

Muntaner, A. I. C., Feichtenberger, E., Leite, Y. R., Rossetti, V. V., Pompeu Junior, J., \& Teófilo Sobrinho, J. (1976). Reação de seleções de limão cravo e de Citrus volkameriana Pasq. a inoculações experimentais de Phytophthora spp. In Anais do $3^{\circ}$ Congresso Brasileiro 
de Fruticultura (p. 127). Rio de Janeiro: Sociedade Brasileira de Fruticultura.

Pio, R. (2005). Propagação de híbridos somáticos de citros e reação à infecção por Phytophthora nicotianae e virus da tristeza dos citros (Tese de doutorado). Escola Superior de Agricultura “Luiz de Queiroz”, Universidade de São Paulo, Piracicaba.

Pompeu Junior, J., \& Blumer, S. (2008). Morte súbita dos citros: suscetibilidade de seleções de limão cravo e uso de interenxertos. Revista Brasileira de Fruticultura, 30(4), 1159-1161.

Rossetti, V. V. (1947). Estudos sobre "gomose de Phytophthora" dos citros: suscetibilidade de diversas espécies cítricas a algumas espécies de Phytophthora. Arquivos do Instituto Biológico, 18, 97-124.

Scott, A. J., \& Knott, M. (1974). A cluster analysis method for grouping means in the analysis of variance. Biometrics, 30, 507-512.

Recebido: Janeiro 31, 2019

Aceito: Junho 18, 2019

Como citar: Blumer, S., \& Pompeu Junior, J. (2019). Reação de seleções do limão Cravo à infecção no tronco por Phytophthora nicotianae e à estirpe protetiva PIAC do vírus da tristeza dos citros. Citrus Research \& Technology, 40, e1047. https://doi.org/10.4322/crt.17919 